\title{
PENDIDIKAN PARENTING PRANIKAH: \\ Upaya Perbaikan Generasi Berkualitas
}

\author{
Khairun Nisa \\ Politeknik Negeri Ujung Pandang \\ Jalan: Tamalanrea Raya (BTP) Makassar \\ Email: khairunnisaibnu@gmail.com
}

\begin{abstract}
Abstrak:
Realitas kehidupan saat ini yang mempertunjukkan kepada fenomena manusia modern yang sudah jauh dari kesadaran spiritualnya. Ini tidak lepas dari peran orang tua yang bertugas untuk menanamkan nilai-nilai keagamaan dalam setiap pribadi anggotanya. Keluarga yang sadar akan pentingnya untuk menanamkan pendidikan keagamaan bagi kehidupan anak-anaknya akan melahirkan pribadipribadi yang memiliki ketahanan spiritual terhadap godaan dan tantangan modernitas, begitu pula sebaliknya. Orang tua merupakan dasar yang paling berpengaruh terhadap keberhasilan perkembangan anak. Namun, saat ini banyak orang tua yang tidak menyadari betapa pentingnya perannya dalam pembentukan kepribadian anak. Banyak orang tua yang secara penuh mempercayakan pendidikan anaknya kepada lembaga-lembaga sekolah tanpa ada sinergi yang baik antara lembaga pendidikan dan orang tua dalam pendidikan anak. Konsep parenting adalah untuk menyiapkan generasi yang kuat dan berkualitas, maka penting bagi calon orang tua membekali diri dengan pendidikan parenting. Karena dalam pendidikan Islam pendidikan parenting terkait dengan pendidikan pra konsepsi, prenatal, dan post natal. Oleh karena itu, calon orang tua wajib memiliki ilmu parenting untuk menghasilkan kualitas yang kuat dan berkualitas.
\end{abstract}

Abstract:

Current life reality has indicated the phenomenon of modern human who have distance from their spiritual awareness. This cannot be separated from the role of parents whose primary task to plant religious values in their family members. Families who are aware of the importance of religious education in the life of their children will definitely create persons with strong spiritual defence towards the challanges of modernity. Conversely, otherwise. Parents is the most influential party in the successfull development of children. However, many parent are currently not aware of their significant role in the personality development of their children. Many parent completely entrust the education of their children to particular school institutions without reliable synergy between the educational institutions and parents for the education of children. As the parenting concept is aimed at preparing strong and high quality generation, it is absolutely important for parents to build their self-capacity with parenting education. This is because in Islamic education, the parenting education is closely linked to pre-conception, pre-natal, and post-natal educations. Therefore, parent candidates must have parenting education in order to generate strong and high quality generations.

Kata kunci:

Keluarga, Pendidikan Parenting 
UNDANG-UNDANG RI Nomor 1 Tahun 1974 menyebutkan pengertian dan tujuan perkawinan terdapat dalam satu pasal, yaitu bab 1 pasal 1 yang menetapkan bahwa "perkawinan adalah ikatan lahir batin antara seorang pria dengan seorang wanita sebagai suami istri dengan tujuan membentuk rumah tangga, keluarga yang bahagia dan kekal berdasarkan Ketuhanan Yang Maha Esa". Dengan demikian jelas bahwa diantara tujuan pernikahan adalah membentuk sebuah rumah tangga yang sakinah, mawaddah dan warahmah.

Keluarga merupakan unit terkecil dalam masyarakat yang anggotanya terdiri dari seorang laki-laki yang berstatus sebagai suami dan seorang perempuan yang berstatuskan sebagai istri serta adanya anak-anak sebagai pelengkap. Islam telah memerintahkan kita untuk menegakkan kehidupan rumah tangga dengan kasih sayang, kecintaan dan ketentraman. Hal ini dimaksudkan untuk mengembangkan keturunan, melahirkan generasi yang diberkahi Allah swt. Keluarga merupakan sekelompok orang yang terdiri dari ayah, ibu dan anak-anak atau suami isteri yang memiliki fungsi tersendiri dalam sebuah keluarga.

Keluarga merupakan subsistem dari sistem sosial, yang menurut alQur'an bukan bangunan di atas tanah kosong. Namun, bagaimana membangun keluarga yang Islami melalui kerja keras dari seluruh anggota keluarga, yang dikomandani oleh suami dan istri sebagai pemimpin didalam rumah tangga. Karenanya, pembentukan keluaraga sakinah pada dasarnya merupakan implementasi dari firman Allah dalam surah al-Tahrīm ayat 6 .

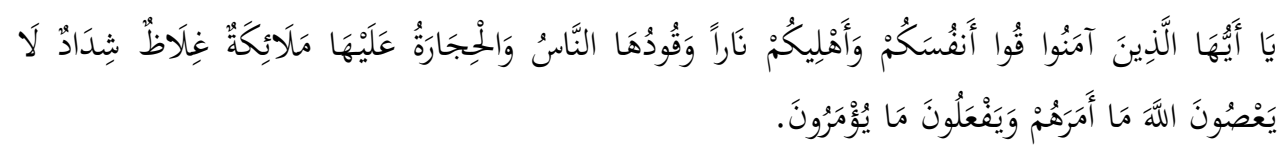

Wahai orang-orang yang beriman! Peliharalah dirimu dan keluargamu dari api neraka yang bahan bakarnya adalah manusia dan batu; penjaganya malaikatmalaikat yang kasar, dan keras, yang tidak durhaka kepada Allah terhadap apa yang Dia Perintahkan kepada mereka dan selalu mengerjakan apa yang diperintahkan.

Memahami ayat tersebut di atas, yang dikehendaki dari keluarga sakinah adalah bagaimana upaya pembinaan keluarga sejak awal (sebelum) pernikahan, pendidikan yang Islami dalam sebuah keluarga dan diselaraskan dengan fungsi manusia untuk beramal di dunia dan akhirat. Dengan demikian diharapkan pasangan yang akan menikah kelak akan dapat membentuk keluarga sakinah pula, keluarga akan mendapatkan ketenangan dan ketentraman. Oleh karena itu diperlukan pula langkah-langkah preventif, selektif dan antisipatif dari setiap individu muslim yang berkeinginan untuk mewujudkan keluarga sakinah. Langkah-langkah preventif, selektif, dan antisipatif berupa pembekalan diri anggota keluarga dengan pendidikan. Jelas bagi orang tua adalah membekali diri dengan pendidikan parenting untuk menghasilkan anak-anak yang berkualitas. 
Pendidikan keluarga merupakan inti dan pondasi dari upaya pendidikan secara keseluruhan. Pendidikan dalam keluarga yang baik merupakan pondasi yang kokoh untuk pendidikan anak selanjutnya, yaitu di sekolah dan masyarakat.

\section{PENDIDIKAN KELUARGA}

Undang-Undang RI No. 20 Tahun 2003 pasal 3 menyebutkan bahwa pendidikan nasional berfungsi untuk mengembangkan kemampuan, membentuk watak serta peradaban bangsa yang bermartabat dalam rangka mencerdaskan kehidupan bangsa, bertujuan untuk berkembangnya potensi peserta didik agar menjadi manusia yang beriman, bertakwa kepada Tuhan Yang Maha Esa, berakhlak mulia, sehat, berilmu, cakap, kreatif, mandiri, dan menjadi warga negara yang demokratis serta bertanggung jawab. Oleh karena itu, pendidikan harus dilaksanakan dengan sebaik-baiknya untuk menciptakan mutu pendidikan yang dapat meningkatkan sumber daya manusia.

Pendidikan merupakan usaha sadar membantu anak dalam menuju kedewasaan baik fisik maupun psikis. Sebagai suatu kegiatan yang sadar akan tujuan dari pendidikan, maka dalam pelaksanaannya berada dalam suatu proses yang berkesinambungan pada setiap jenis dan jenjang pendidikan yang semuanya berkaitan dalam suatu sistem pendidikan yang integral. Pendidikan dengan pendekatan holistic-integratif yang dikembangkan oleh Tilaar mendefinisikan pendidikan sebagai suatu proses menumbuhkembangkan peserta didik yang memasyarakat, membudaya, dalam tata kehidupan yang berdimensi lokal, nasional, dan global. ${ }^{1}$

Pendidikan mempunyai peranan yang sangat menentukan bagi perkembangan dan perwujudan diri individu terutama bagi pembangunan bangsa dan negara. Tujuan pendidikan pada umumnya adalah membantu siswa untuk mengembangkan kompetensi-kompetensi yang telah dimiliki. Dapat disimpulkan bahwa pendidikan merupakan sebuah proses mengeksplorasi dan memaksimalkan potensi-potensi manusia yang secara alamaiah dimiliki semenjak lahir agar ketika hidup dapat lebih mengerti tentang hal-hal yang terjadi di sekitarnya.

Lingkungan keluarga adalah segala sesuatu yang berada dalam kelompok sosial kecil yang berfungsi untuk melindungi setiap anggotanya, yang terdiri dari ayah, ibu, dan anak yang memiliki hubungan darah, rasa kasih sayang diantara mereka. Dalam dunia pendidikan lingkungan keluarga memiliki fungsi yang paling utama untuk membentuk karakter bagi seoarang anak, karena lingkungan kelurga merupakan lingkungan pertama seorang anak belajar sebelum mereka berada dalam lingkungan sekunder (lingkungan sekolah dan masyarakat).

Keluarga sangat penting dalam proses sosialisasi, menurut Narwoko dan Suyanto, keluarga dihadapkan kepada tiga hal. Pertama, keluarga merupakan 
kelompok primer yang selalu tatap muka di antara anggotanya, selalu mengikuti perkembangan anggota anggotanya. Kedua, orang tua mempunyai kondisi yang tinggi untuk mendidik anak-anaknya, yang menimbulkan hubungan emosional di mana hubungan ini sangat diperlukan dalam proses sosialisasi. Ketiga, adanya hubungan sosial yang tetap, maka dengan sendirinya orang tua mempunyai peranan yang penting terhadap proses sosialisasi anak. $^{2}$

Orang tua (dalam hal ini ayah dan ibu) dalam sebuah keluarga sangat dibutuhkan dalam membantu anak untuk memiliki dan mengembangkan dasar-dasar pendidikan nilai. Keluarga yang utuh akan memberikan peluang besar untuk mengembangkan cara-cara yang efektif dalam mengarahkan, membimbing, dan membantu anaknya menyatu dalam suatu makna keluarga dan berinteraksi dengan lingkungan masyarakat.

Menurut Arief Rohman ${ }^{3}$ menjelaskan bahwa keluarga memiliki fungsi sebagai berikut:

1. Fungsi Proteksi, keluarga harus memberikan perlindungan, perawatan, serta menjaga dari setiap gangguan yang dapat mengancam keselamatan anggota keluarganya.

2. Fungsi rekreasi, keluarga harus $m$ emberikan dan menciptakan rasa damai, tentram dan gemberi sehingga lingkungan keluarga memberikan sarana hiburan bagi anak.

3. Fungsi inisiasi, keluarga harus mengenalkan kepada anak tentang hal hal yang berada disekitar lingkungannya, seperti nama hewan, nam a kelurga yang lain, saudara, dan tetanga agar anak mengenal lingkungan sekitarnya.

4. Fungsi sosialisasi, anak harus diberikan pendidikan mengenai adat istiadat, budaya yang diterapkan di lingkungan yang ditempati agar anak dapat hidup baik dengan masyarakat setempat.

5. Fungsi edukasi, anak hari diberi pendidikan sejak dini baik yang bersifat pengetahuan maupun yang bersifat budaya. Agar anak bisa tumbuh menjadi anak yang cerdas dan bermoral.

Keluarga merupakan lingkungan pendidikan pertama bagi anak, dimana pendidiknya adalah kedua orang tua mereka. Pendidikan keluarga merupakan pendidikan alamiah yang melekat pada setiap bangunan rumah tangga. Institusi keluarga memiliki peranan penting dalam proses pendidikan anak, karena sebelum anak masuk pada lingkungan sekolah dan masyarakat, ia terlebih dahulu memperoleh pendidikan di lingkungan keluarga.

\section{URGENSI PARENTING DALAM KELUARGA}

Sebelum kita membahas tentang urgensi parenting dalam keluarga, terlebih dahulu kita bahas tentang makna dari parenting itu sendiri. Parenting berasal dari bahasa Inggris yang berasal dari kata parent yang berarti orang tua. ${ }^{4}$ Sedangkan dalam kamus Oxford, parenting adalah the process of caring for 
your child or children. ${ }^{5}$ Penjelasan oleh Martin Davies tentang parenting yaitu process of promoting and supporting the physical, emotional, social, and the intellectual development of a child from infancy to adulthood. ${ }^{6}$ Mendidik atau pendidikan anak dalam bahasa Arab "tarbiyah al-Awlad". Arti tarbiyah merupakan proses menumbuhkan dan mengembangkan apa yang ada dalam diri anak baik secara fisik, psikis, social, maupun spiritual. ${ }^{7}$ Arti aulad secara bahasa merupakan jamak dari kata waladun yang berarti anak. ${ }^{8}$

Berdasarkan beberapa pengertian di atas, penulis menyimpulkan bahwa proses mengasuh/mendidik anak, orang tua berperan untuk mengembangkan potensi anak dari lahir hingga mereka dapat bertanggung jawab terhadap dirinya sendiri. Peran penting orang tua dapat dilihat dari empat sudut pandang, yaitu: normatif, yuridis, psikologis, dan sosiologis.

Secara normatif, orang tualah yang bertugas untuk mencerdaskan anak meskipun anak telah memasuki usia sekolah. Orang tua berperan besar dalam megembangkan potensi anak. Sebagaimana dalam surah at-Tahrim ayat 6 yang artinya "haai orang0orang yang beriman, peliharah dirimu dan keluargamu dari api neraka". ${ }^{9}$ Sejalan dengan itu, dalam hadis Nabi saw. disebutkan bahwa:

$$
\text { كل مولود يولد على الفطرة فأبواه يهودانه أو ينصراه أو يمجسانه }
$$

Setiap yang dilahirkan dalam keadaan suci (fitrah), maka orang tuanyalah yang menjadikannya Yahudi, nasrani, dan Majusi. ${ }^{10}$

Secara yuridis, disebutkan dalam Undang-Undang Sisdiknas Nomor 20 Tahun 2003 pasal 7 ayat 2 menyebutkan bahwa "orang tua dari anak usia wajib belajar, berkewajiban memberikan pendidikan dasar kepada anaknya." 11

Secara psikologis dikatakan bahwa manusia adalah makhluk "psychophysics neutral" yang berarti makhluk yang memiliki kemandirian jasmaniah dan rohaniah. ${ }^{12}$ Kemandirian dalam hal ini adalah potensi yang dapat tumbuh dan berkembang dipengaruhi oleh lingkungan yang mendidiknya. Oleh karena itu peran orang tua sangat besar dalam mengembangkan potensi anak terutama dalam masa-masa perkembangannya.

Secara sosiologis, manusia merupakan makhluk "homo-socius" yaitu berwatak dan berkemampuan dasar atau yang memiliki garizah (insting) untuk hidup bermasyarakat. ${ }^{13}$ Jadi manusia merupakan makhluk social yang akan berinteraksi dengan kelompok dalam lingkungannya. Dalam proses proses berinteraksi, manusia membutuhkan aturan-aturan yang seharusnya ini telah diperoleh dalam lingkungan keluarganya.

Tentu menjadi problem dan menggelisahkan bagi setiap manusia ketika realitas kehidupan saat ini yang dihadapi mempertunjukkan kita pada fenomena manusia modern yang sudah jauh dari kesadaran spiritualnya. Ini tidak lepas dari peran orang tua yang bertugas untuk menanamkan nilai-nilai 
keagamaan dalam setiap pribadi anggotanya. Keluarga yang sadar akan pentingnya untuk menanamkan pendidikan keagamaan bagi kehidupan anakanaknya akan melahirkan pribadi-pribadi yang memiliki ketahanan spiritual terhadap godaan dan tantangan modernitas, begitu pula sebaliknya.

Orang tua memiliki tanggung jawab besar terhadap pendidikan anakanaknya. Terutama bagi seorang ibu, yang merupakan madrasah utama bagi anak-anaknya. Dalam buku Fauzi Rachman menyebutkan bahwa ibu yang kuat dan ceria akan melahirkan anak yang ceria dan kuat, sebaliknya ibu yang pemuruung akan menghasilkan anak yang pemurung pula. ${ }^{14}$ Selain ibu, ayah tentu memiliki peran yang sangat besar pula dalam mendidik anak dan mengajari mereka tentang akidah, ibadah dan moralitas seorang anak. Sebagaimana dalam surah Luqman ayat 13 dan 14. Jadi tanggung jawab mendidik anak itu merupakan tanggung jawab utuh kedua orang tua, dan tidak menekankan kepada salah satu pihak saja.

Fenomena zaman sekarang, banyak orang tua yang salah kaprah dalam pendidikan anaknya. Mereka menganggap bahwa hanya sekolahlah yang bertanggung jawab terhadap pendidikan anak-anaknya, sehingga orang tua menyerahkan sepenuhkan pendidikan anak-anaknya kepada pihak sekolah. ${ }^{15}$ Oleh karena itu, banyak orang tua menjadikan mendidik dan mengasuh menjadi "parttime job" saja.

Menghasilkan generasi yang tangguh dan berkualitas, tentu diperlukan usaha yang konsisten dan kontinyu dari orang tua dalam melaksanakan tugasnya untuk memelihara, mengasuh dan mendidik anak-anaknya. Proses mendidik dan mengasuh bukanlah proses yang instant, membutuhkan banyak waktu dan tentunya usaha yang besar dimulai dari memilih jodoh terbaik yang akan menjadi partner dalam mengasuh/mendidik anak, saat anak dalam kandungan dan saat anak telah lahir ke dunia.

Oleh karena itu, sebagai calon orang tua tentulah sangat memerlukan pendidikan terutama pendidikan parenting. Apabila seseorang telah mantap untuk hidup berkeluarga seharusya berbanding lurus dengan kebutuhan untuk memperdalam pengetahuannya tentang pendidikan parenting pranikah. Dalam hal ini, kementerian agama telah menfasilitasi dengan pengadaan kursus calon pengantin, hanya saja masih banyak yang mengabaikan usaha pemerintah untuk pembaikan kualitas keluarga.

\section{SIMPULAN}

Anak merupakan amanah yang telah dititipkan oleh Allah kepada para orang tua. Oleh karena itu, orang tua wajib menjaga dan memelihara amanah itu dengan baik. Kalau saja kita dititipi amanah untuk menjaga anak presiden, tentulah kita akan menjaga dengan sebaik mungkin. Apalagi yang menitipkan anak sebagai amanah ini langsung dari Allah, maka kita harus bertanggung jawab terhadap amanah tersebut. 
Seorang anak yang memiliki dasar agama secara aqidah, moral, ibadah, sistem hidup dan syariat serta pelaksanaannya, maka ia akan memiliki benteng yang kuat untuk menghadapi hal-hal yang menyimpang dari ajaran agama. Tentunya orang tua harus memiliki bekal ilmu yang banyak dalam mendidik anak-anak zaman sekarang. Oleh karena itu, sangatlah penting bagi calon orang tua memiliki pendidikan parenting.

Proses menjalankan peran sebagai orang tua perlu konsekuensi dan kesabaran dalam pelaksanaanya. Dan inilah yang sulit dilakukan oleh para orang tua sehingga ia melimpahkan pendidikan anak-anaknya kepada sekolah atau lembaga pendidikan yang diinginkan. Padahal ini bukan solusi sepenuhnya, dengan pengawasan bersama antara orang tuadan lembaga pendidikan maka akan terwujud karakter anak sesuai dengan yang diharapkan.

\section{CATATAN AKHIR:}

1. Tilaar, Pendidikan, Kebudayaan, Masyarakat Madani Indonesia, Bandung: Rosdakarya, 2000.

2. Narwoko dan Suyanto, Sosialisasi Teks Pengantar dan Terapan, Jakarta: Pernada Media Group, 2004.

3. Arif Rohman, Memahami Pendidikan dan Ilmu Pendidikan, Yogyakarta: LaksBang Mediatama, 2011, h. 199.

4. John M. Echols dan Hassan Shadily, Kamus Inggris Indonesia, Jakarta: Gramedia Pustaka Utama, h. 418.

5. A. S. Hornby, Oxford Advanced Learner's Dictionary of Current English, New York: Oxford University Press, 2010, h. 1067.

6. Martin Davies, Parenting: Wikipedia, the free encyclopedia. Html, 12 November 2016, Pukul 11.07

7. Abdul Mujib dan Jusuf Mudzakkir, Ilmu Pendidikan Islam, Jakarta: Prenada Media Group, 2005, h. 10-11.

8. Ahmad Warson Munawir, Kamus Al-Munawwir, Surabaya: Pustaka Progressif, 1997, h. 1580 .

9. Departem Agama RI, Al-Qur'an dan Terjemahnya, Jakarta: Departemen Agama, 2003 .

10. Imam Abi 'Abdillah Muhamad bin Ismail bin Ibrahim bin Mughirah, Shahih Bukhari, Juz 1, Beirut: Dār al-Kutub al-Ilmiyah, t.th., h. 421.

11. Undang-Undang Republik Indonesia No. 20 Tahun 2003, Sistem Pendidikan Nasional, Pasal 7 ayat 3.

12. M. Arifin, Hubungan Timbal Balik Pendidikan Agama Islam, Jakarta: Bulan Bintang, 2004. h. 56.

13. Sururin, Ilmu Jiwa Agama, Jakarta: Raja Grafindo Persada, 2004, h. 1.

14. M. Fauzi Rachman, Islamic Parenting, Jakarta: Erlangga, 2011, h. 11.

15. Hasbullah, Dasar-dasar Pendidikan, Jakarta: Raja Grafindo Persada, 2005, h. 22.

\section{DAFTAR PUSTAKA}

Hornby, A. S. Oxford Advanced Learner's Dictionary of Current English. New York: Oxford University Press, 2010. 
Mujib, Abdul dan Jusuf Mudzakkir. Ilmu Pendidikan Islam. Jakarta: Prenada Media Group, 2005.

Ahmad Warson Munawir. Kamus Al-Munawwir. Surabaya: Pustaka Progressif, 1997.

Al-Jauhari. Membangun Keluarga Qur'ani. Jakarta: Amzah, 2005.

Rohman, Arif. MemahamiPendidikan (Ilmu Pendidikan). Surabaya: LBM, 2009.

Aunurrahman. Belajar dan Pembelajaran. Bandung: Alfabeta, 2009.

Baidan, Nashruddin. Wawasan Baru Ilmu Tafsir. Yogyakarta: Pustaka Pelajar, 2005

Darajat, Zakiyah. IlmuPendidikan Islam. Jakarta: PT BumiAksara, 2008.

Departemen Agama RI. Al-Qur'an dan Terjemahnya. Jakarta: Departemen Agama, 2003.

El Mubarak, Zaim. Membumikan Pendidikan Nilai. Bandung: Alfabeta, 2009.

Hasbullah. Dasar-dasar Pendidikan. Jakarta: Raja Grafindo Persada, 2005.

Imam Abi 'Abdillah Muhamad bin Ismail bin Ibrahim bin Mughirah, Shahih Bukhari, Juz 1, Beirut, Daar al-Kutub al-Ilmiyah,tth.

Echols, John M. dan Hassan Shadily. Kamus Inggris Indonesia. Jakarta: Gramedia Pustaka Utama.

Koesoema A. Doni. Pendidikan Karakter Strategi Pendidikan Anak di Zaman Global. Jakarta: Grasindo, 2007.

Arifin, M. Hubungan Timbal Balik Pendidikan Agama Islam. Jakarta: Bulan Bintang, 2004.

Rachman, M. Fauzi. Islamic Parenting. Jakarta: Erlangga, 2011.

Mansur. Pendidikan Anak Usia Dini dalam Islam. Yogyakarta: Pustaka Pelajar, 2007.

Davies, Martin. Parenting: Wikipedia, the Free Encyclopedia. Html, 12 November 2016, Pukul 11.07

Mudyahardjo, Redja. Pengantar Pendidikan. Jakarta: Raja GrafindoPersada, 2009.

Mujib, Abdul dan Jusuf Mudzakkir. Ilmu Pendidikan Islam. Jakarta: Kencana Prenada Media, 2006.

Mulyana, Rohmat. Mengartikulasikan Pendidikan Nilai. Bandung: Alfabeta, 2004.

Narwoko dan Suyanto. Sosialisasi Teks Pengantar dan Terapan. Jakarta: Pernada Media Group, 2004

Prayitno. Dasar Teori dan Praksis Pendidikan. Jakarta: Grasindo, 2007.

Shaleh. Pendidikan Agama \& Pembangunan Watak Bangsa. Jakarta: PT Raja Grafindo Persada, 2005.

Soyomukti, N. Teori-Teori Pendidikan. Jogjakarta: Ar-Ruzz Media, 2010.

Sururin. Ilmu Jiwa Agama. Jakarta: Raja Grafindo Persada, 2004.

Syahidin. Menelusuri Metode Pendidikan dalam Al-Qur'an. Bandung: Alfabeta, 2009.

Tilaar. Pendidikan, Kebudayaan, Masyarakat Madani Indonesia. Bandung: Rosdakarya, 2000

Undang-Undang Republik Indonesia No. 20 Tahun 2003, Sistem Pendidikan Nasional, Pasal 7 ayat 3. 